\title{
Effects of Carbon Dioxide on Serum Biochemical Patterns and on Histopathological Changes of Organs in Rats
}

\author{
Hisateru Mitsuda, Saburo Ueno, Hiroshi Mizuno, \\ Tadashi UEDA, Hiromi FuJIKAWA, \\ Tomoko NOHARA, and Chieko FUKADA ${ }^{1}$ \\ Interdisciplinary Research Institute of Environmental Sciences, \\ Kawaramachi Kojinguchi-agaru, Kamigyo-ku, Kyoto 602, Japan
}

(Received May 23, 1981)

\begin{abstract}
Summary The effects of carbon dioxide on serum biochemical patterns and on histopathological changes of organs were studied in male SpragueDawley rats which were anesthetized with a mixture of $40 \%$ carbon dioxide and $60 \%$ oxygen for $3 \mathrm{hr}$. This level of carbon dioxide is sufficient to maintain rats at an anesthetized level. There were gradual decreases in respiration, body temperature, heart rate, blood pressure and blood $\mathrm{pH}$. At the same time there were significant increases in organ weight (lungs and kidneys), and in exudate to thorax, hematocrit, and serum biochemical patterns (glucose, phosphorus, uric acid, blood urea nitrogen, glutamic pyruvic transaminase, glutamic oxaloacetic transaminase and $\alpha$-hydroxybutyrate dehydrogenase). The weight of the liver, however, decreased slightly. There were minor abnormalities in both gross anatomy and histology (lungs, liver and kidneys). When the rats inhaled ordinary air, they awoke within a few minutes and recovered normal hematological levels ( $\mathrm{pH} \mathrm{7.3,} \mathrm{PaO}_{2} 120 \mathrm{mmHg}$ and $\mathrm{PaCO}_{2} 45 \mathrm{mmHg}$ ) within $24 \mathrm{hr}$.

Key Words carbon dioxide, serum biochemical patterns, histopathological changes
\end{abstract}

Following Hickman's $(l)$ description of the anesthetic effects of carbon dioxide in dogs, few studies were made on the effects in mammals of $\mathrm{CO}_{2}$ as an anesthetic, until Graham et al. $(2,3)$ reported that dogs could be anesthetized with carbon dioxide for more than $1 \mathrm{hr}$ without blood pressure or electrocardiographic (ECG) abnormalities occurring. They found that a 20-75\% level of $\mathrm{CO}_{2}$ (plus in combination with $80-25 \% \mathrm{O}_{2}$ ) was required to keep the animals under sedation, and that $80 \% \mathrm{CO}_{2}$ was the critical point at which the $\mathrm{CO}_{2}$ concentrations became lethal.

Mitsuda et al.(4) drew attention to the fact that the germination rate of

\footnotetext{
${ }^{1}$ 滿田久輝，上野三郎，水野 洋，上田忠司，藤川広美，野原智子，深田千枝子
} 
unhulled rice could be maintained at the very high level of $95 \%$ or more when the rice was kept in an atmosphere of carbon dioxide for even as long as several years. He hypothesized that hibernation in toads might be controlled by a combination of low temperature and accumulation of carbon dioxide in the earth in which the toads bury themselves and remain throughout the winter.

The purpose of the present paper is to determine the physiological significance of carbon dioxide anesthesia on serum biochemical patterns and on histopathological changes of organs in rats.

\section{MATERIALS AND METHODS}

In order to investigate the complicated physiological effects of carbon dioxide in animals, various methods must be employed. Comparative results between rats under $\mathrm{CO}_{2}$ anesthesia and a control group were obtained for serum biochemical patterns, partial gas pressure in arterial blood, and physiological functions (body temperature, respiration, heart rate and blood pressure). Autopsies and histopathological studies were also performed. Six hundred male Sprague-Dawley (S. D.) rats, eight weeks old, were used as the experimental animals. The rats were fed on commercial diet and bred in aseptic cages before use. They were pre-anesthetized with pentobarbital, $50 \mathrm{mg}$ per $\mathrm{kg}$ body weight by intraperitoneal injection just prior to the experiment.

A control group of two hundred rats was kept in the same conditions but allowed to breathe ordinary air. The experiments were conducted at room temperature.

Gas mixture. The gas mixture inhaled by the experimental group was a $40 \%$ $\mathrm{CO}_{2}-60 \% \mathrm{O}_{2}$ mixture produced in the apparatus diagrammed in Fig. 1. This $\mathrm{CO}_{2}$ level is sufficient to keep the rats under anesthesia. Tracheotomies were performed on the animals to ensure the maintenance of accurate inhalation of the gas.

Measurement of physiological functions. Heart rate, respiration and blood pressure were recorded using sensors set in a polygraph RM-6200 (Nihon Koden Co., Ltd., Japan). Body temperature was taken using a rectal thermometer, and

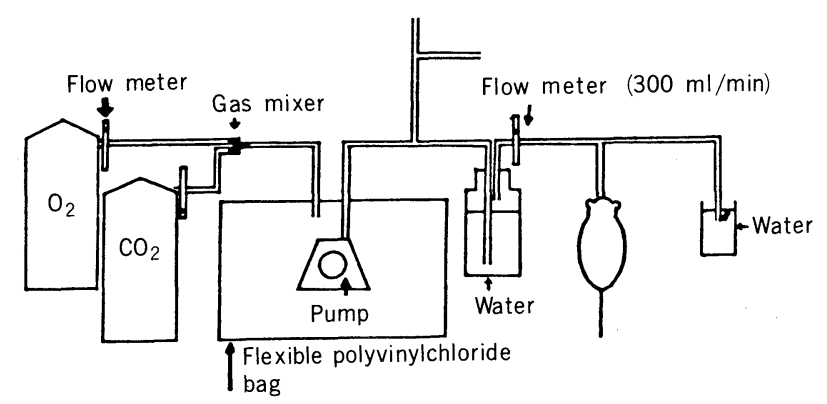

Fig. 1. The experimental apparatus. 
serum biochemical patterns (total protein, albumin, glucose, triglyceride, inorganic P, uric acid, BUN, GOT, GPT, LDH, $\alpha-\mathrm{HBD}$, and AlP) were measured with a standard serological analyzer RaBA Super System (Chūgai Pharmaceutical Co., Ltd., Japan). Hematocrit values were obtained by the standard centrifugal method of McGovern. Blood was drawn using a polyethylene tube catheter inserted in the common carotid artery, and the partial pressures of both carbon dioxide and oxygen were measured with a blood gas analyzer IL-203-05 (Instrumentation Laboratory, U.S.A.). Histopathological examinations were made of preparations of liver, heart and lung tissue with hematoxylin-eosin, and of preparations of kidney tissue stained with periodic acid-schiff. In order to determine the typical effects of carbon dioxide on the tissues of liver, kidneys, spleen, lungs and heart, the gas was inhaled for 5 to $360 \mathrm{~min}$ at room temperature.

\section{RESULTS}

The effects of carbon dioxide on heart rate, respiration, body temperature and blood pressure

In the experimental group that inhaled $\mathrm{CO}_{2}$ gas, there was a gradual decrease in respiration, heart rate, body temperature and blood pressure as shown in Figs. 2 and 3. The abrupt rises and falls in heart rate, respiration and blood pressure were observed immediately after the inhalation of $\mathrm{CO}_{2}$ gas. The abrupt falls may be caused by the unusually high concentration of $\mathrm{CO}_{2}$ in the inhaled air, and the following rises may be due to the biological regulation mechanism of the rats. In the control group which was allowed to inhale ordinary air, there was a gradual increase in both respiration and heart rate. Body temperature decreased in the control group during the first hour and then began to increase, probably because of awaking from anesthesia with pentobarbital. The blood pressure of the control group remained slightly higher than the pre-experimental level. The four biological functions of blood pressure, body temperature, respiration and heart rate were not recorded for a full 3-hr period because the animals began to awaken from the preanesthesia after $1.5 \mathrm{hr}$. The experimental group was maintained at a stable anesthetized level for the entire $3 \mathrm{hr}$ by the presence of the $40 \% \mathrm{CO}_{2}-60 \% \mathrm{O}_{2}$ mixture.

The effects of carbon dioxide on the levels of exudate to thorax and ascites, and on organ weight

The most serious effects of carbon dioxide included respiratory acidosis, which was followed by metabolic disorders in the respiratory and circulatory systems of the experimental animals. Functional disorders of the lungs, liver and kidneys may cause fatalities if the gas is inhaled continuously over a long period of time. However, for the short periods of the experiments, the animals were able to recover rapidly from adverse effects when allowed to breathe ordinary air, because the $\mathrm{CO}_{2}$ was quickly excreted from their bodies.

Vol. 28, No. 2, 1982 


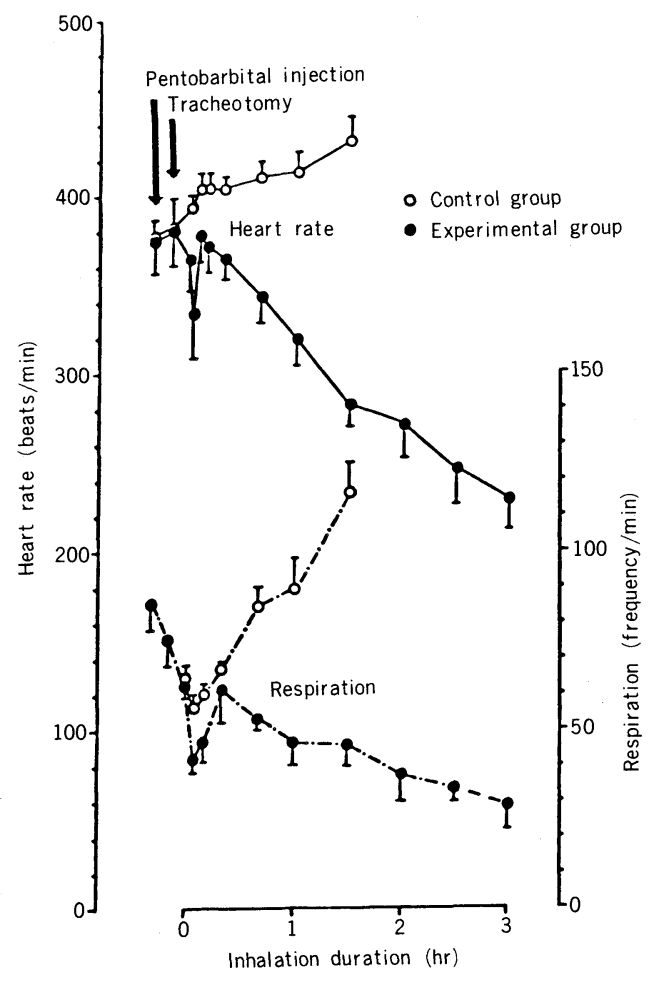

Fig. 2. The effects of carbon dioxide on heart rate and respiration. In the experimental group, heart rate and respiration decreased gradually but in the control group, there was a remarkable increase in both heart rate and respiration due to gradual recovery from pentobarbital anesthesia. Each point represents a mean \pm SE.

Table 1 shows the amount of exudate to thorax and ascites and the organ weight in four groups of rats; the first group is the control, inhaling ordinary air; the second is the experimental group, inhaling carbon dioxide gas for $3 \mathrm{hr}$; the third is a recovery group which inhaled carbon dioxide gas for $3 \mathrm{hr}$ and then ordinary air for $5 \mathrm{hr}$; and the fourth is another recovery group which inhaled carbon dioxide gas for $3 \mathrm{hr}$ followed by inhaling ordinary air for $24 \mathrm{hr}$. The physiological effects of carbon dioxide can be seen here to be deleterious, but not substantially toxic because all functions return to pre-experimental levels within $24 \mathrm{hr}$ at the latest.

The effects of carbon dioxide on the hematological and serum biochemical patterns

Table 2 shows typical effects of $\mathrm{CO}_{2}$ on hematological and serum biochemical patterns. The significant increase in hematocrit relates to both the respiratory acidosis and exudate to thorax indicated in Table 1.

The increases of glucose, inorganic phosphorus, uric acid, blood urea nitrogen (BUN), glutamic oxaloacetic transaminase (GOT), glutamic pyruvic transaminase 


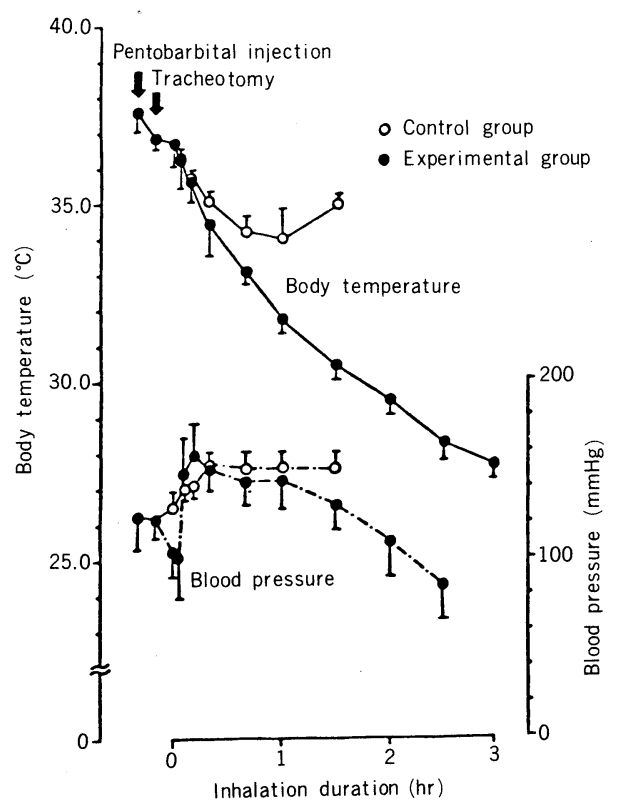

Fig. 3. The effects of carbon dioxide on body temperature and blood pressure. There was a significant fall in body temperature in the experimental group. In the experimental group, blood pressure showed extreme fluctuations. Each point respresents a mean $\pm \mathrm{SE}$.

Table 1. Effects of carbon dioxide on the level of exudate to thorax and ascites, and on organ weight in rats. There was a remarkable increase in exudate to thorax and in weight of the lungs and kidneys, but the weight of the liver decreased. When the rats inhaled ordinary air, abnormalities both in the increase in exudate to thorax and organ weight returned to normal levels within 5 to $24 \mathrm{hr}$.

\begin{tabular}{lccccc}
\hline & & Control & $\begin{array}{c}\text { Experimental } \\
\text { group }\end{array}$ & $\begin{array}{c}\text { Recovery group } \\
\text { (inhaled ordinary } \\
\text { air for 5 hr) }\end{array}$ & $\begin{array}{c}\text { Recovery group } \\
\text { (inhaled ordinary } \\
\text { air for 24 hr) }\end{array}$ \\
\hline $\begin{array}{l}\text { Exudate } \\
\text { to thorax }\end{array}$ & $(\mathrm{mg})$ & $145 \pm 95$ & $758 \pm 353^{* * *}$ & $158 \pm 221$ & $147 \pm 108$ \\
$\begin{array}{l}\text { Ascites } \\
(\mathrm{mg})\end{array}$ & $632 \pm 154$ & $837 \pm 382$ & $657 \pm 355$ & $596 \pm 234$ \\
\hline $\begin{array}{l}\text { Organ weight } / 100 \mathrm{~g} \text { of body weight } \\
\text { Heart }\end{array}$ & $(\mathrm{mg})$ & $344 \pm 45$ & $343 \pm 29$ & $376 \pm 25$ & $387 \pm 37^{*}$ \\
Lungs & $(\mathrm{mg})$ & $464 \pm 55$ & $642 \pm 182^{* *}$ & $538 \pm 55^{* *}$ & $518 \pm 74$ \\
Liver & $(\mathrm{g})$ & $5.02 \pm 0.42$ & $4.32 \pm 0.46^{* *}$ & $4.72 \pm 0.29$ & $4.68 \pm 0.39$ \\
Spleen & $(\mathrm{mg})$ & $259 \pm 32$ & $231 \pm 30$ & $266 \pm 26$ & $284 \pm 45$ \\
Kidneys & $(\mathrm{mg})$ & $815 \pm 44$ & $911 \pm 92^{* *}$ & $866 \pm 57^{*}$ & $866 \pm 67$ \\
\hline
\end{tabular}

${ }^{*} p<0.05,{ }^{* *} p<0.01,{ }^{* * *} p<0.001$.

Vol. 28, No. 2, 1982 
Table 2. The effects of carbon dioxide on the hematological and serum biochemical patterns. There were significant increases in hematocrit, glucose, inorganic $\mathrm{P}$, uric acid, BUN, GOT, GPT, and $\alpha$-HBD. When the rats inhaled ordinary air, normal levels were restored within 5 to $24 \mathrm{hr}$ except for GOT.

\begin{tabular}{|c|c|c|c|c|c|}
\hline & & Control & $\begin{array}{l}\text { Experimental } \\
\text { group }\end{array}$ & $\begin{array}{l}\text { Recovery group } \\
\text { (inhaled ordinary } \\
\text { air for } 5 \mathrm{hr} \text { ) }\end{array}$ & $\begin{array}{l}\text { Recovery group } \\
\text { (inhaled ordinary } \\
\text { air for } 24 \mathrm{hr} \text { ) }\end{array}$ \\
\hline Hematocrit & $(\%)$ & $44.0 \pm 1.9$ & $54.3 \pm 5.4 * * *$ & $46.6 \pm 2.3^{*}$ & $43.8 \pm 5.4$ \\
\hline $\begin{array}{l}\text { Total } \\
\text { protein }\end{array}$ & $(\mathrm{g} / \mathrm{dl})$ & $4.74 \pm 0.24$ & $4.51 \pm 0.37$ & $4.57 \pm 0.31$ & $4.54 \pm 0.24$ \\
\hline Albumin & & $2.51 \pm 0.13$ & $2.37 \pm 0.22$ & $2.59 \pm 0.20$ & $2.40 \pm 0.13$ \\
\hline Glucose & $(\mathrm{mg} / \mathrm{dl})$ & $196.1 \pm 32.1$ & $315.9 \pm 60.8^{* * *}$ & $180.5 \pm 32.0$ & $176.5 \pm 37.5$ \\
\hline Triglyceride & ", & $191.4 \pm 101.1$ & $187.9 \pm 67.0$ & $132.2 \pm 40.9$ & $119.1 \pm 58.2$ \\
\hline Inorganic $\mathrm{P}$ & , & $8.12 \pm 0.76$ & $13.97 \pm 2.48^{* * *}$ & $7.69 \pm 1.04$ & $8.73 \pm 1.02$ \\
\hline Uric acid & , & $1.54 \pm 0.42$ & $2.50 \pm 0.79 * *$ & $1.72 \pm 0.63$ & $1.36 \pm 0.19$ \\
\hline BUN & & $17.05 \pm 2.56$ & $20.55 \pm 3.27 * *$ & $20.58 \pm 3.30 *$ & $18.77 \pm 3.76$ \\
\hline GOT & (IU/liter) & $67.19 \pm 4.46$ & $98.30 \pm 29.18^{* *}$ & $135.3 \pm 38.1 * * *$ & $75.06 \pm 8.47^{*}$ \\
\hline GPT & , & $24.02 \pm 4.00$ & $35.51 \pm 6.78^{* * *}$ & $44.68 \pm 14.19 * * *$ & $22.86 \pm 2.23$ \\
\hline LDH & " & $552.0 \pm 215.9$ & $706.6 \pm 183.4$ & $688.5 \pm 294.6$ & $502.9 \pm 202.6$ \\
\hline$\alpha$-HBD & " & $211.8 \pm 81.5$ & $288.9 \pm 68.5^{*}$ & $255.2 \pm 64.6$ & $216.5 \pm 84.3$ \\
\hline AlP & " & $481.1 \pm 96.1$ & $472.3 \pm 116.9$ & $477.0 \pm 92.3$ & $514.3 \pm 162.7$ \\
\hline
\end{tabular}

${ }^{*} p<0.05,{ }^{* *} p<0.01,{ }^{* * *} p<0.001$.

(GPT), and $\alpha$-hydroxybutyrate dehydrogenase $(\alpha$-HBD) in serum are due to functional disorders in the liver and kidneys caused by respiratory acidosis. Nevertheless, the normal pattern of serum biochemical levels soon returned after inhalation of ordinary air by the rats. Therefore, we have concluded that the harmful effects of $\mathrm{CO}_{2}$ on these functions are mild and temporary.

The effects of carbon dioxide on pHa, $\mathrm{PaCO}_{2}$ and $\mathrm{PaO}$ levels in carotid arterial blood

Figure 4 shows the physiological levels of $\mathrm{pHa}, \mathrm{PaCO}_{2}$ and $\mathrm{PaO}_{2}$ in blood from the carotid artery. pHa decreased in two stages, the first sudden and the second more gradual, while $\mathrm{PaCO}_{2}$ gradually increased and $\mathrm{PaO}_{2}$ fluctuated.

It is quite possible, however, that the $\mathrm{PaO}_{2}$ depressed level was caused by decreased respiration, and that the unusually rapid recovery of $\mathrm{pHa}, \mathrm{PaO}_{2}$ and $\mathrm{PaCO}_{2}$ resulted from the very rapid excretion of $\mathrm{CO}_{2}$ from the animals when allowed to breathe ordinary air.

The effects of carbon dioxide on the histopathological findings on liver, lungs, kidneys and spleen

The results are summarized in Table 3. It appears that carbon dioxide attacks the lungs, kidneys, liver and spleen. The histopathological findings suggest that the 


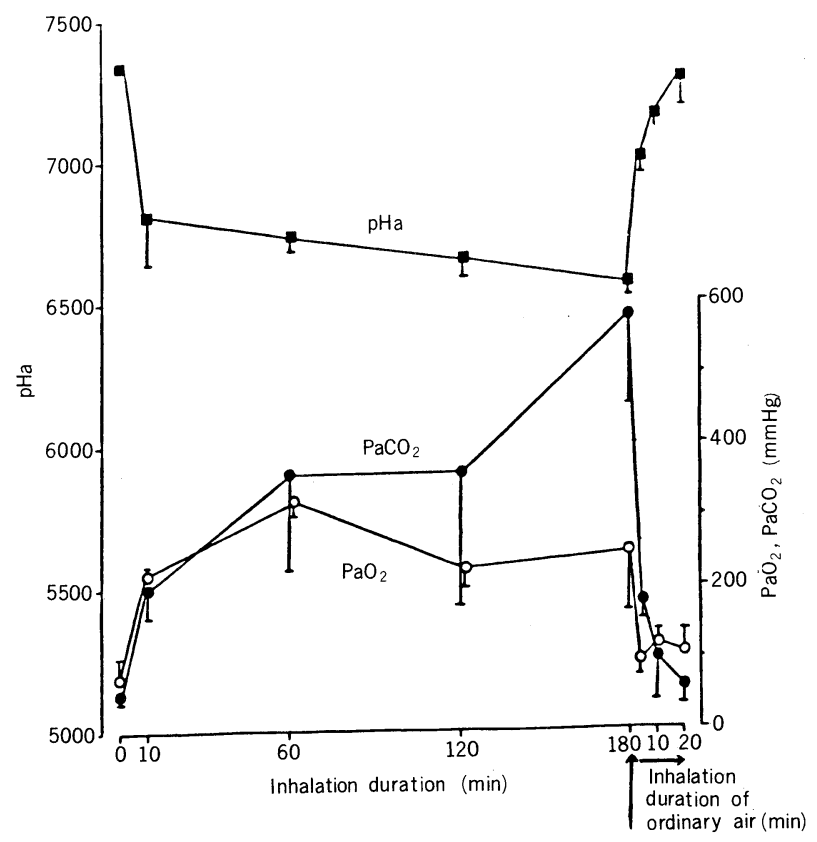

Fig. 4. The effects of carbon dioxide on levels of $\mathrm{pHa}, \mathrm{PaCO}_{2}$ and $\mathrm{PaO}_{2}$ in carotid arterial blood and recovery patterns. $\mathrm{pHa}$ decreased abruptly at first and then more gradually. $\mathrm{PaCO}_{2}$ gradually increased but $\mathrm{PaO}_{2}$ fluctuated. On inhalation of ordinary air, all three levels rapidly returned to normal. Each point represents a mean $\pm \mathrm{SE}$.

effects are only slight, and that normal functioning resumes when the animals are removed from the gaseous condition and returned to ordinary air.

\section{DISCUSSION}

In the present study, rats were anesthetized with a mixture of $40 \%$ carbon dioxide and $60 \%$ oxygen for $3 \mathrm{hr}$. The carbon dioxide alone was sufficient to maintain the animals at an anesthetized level. The results obtained here were similar to those of Graham et al. $(2,3)$ who concluded that dogs could be anesthetized with mixtures of 20 to $75 \% \mathrm{CO}_{2}$ (the remainder being oxygen) for more than $1 \mathrm{hr}$ without any significant changes in physiological functions when appropriate artificial ventilation was applied.

Johnson et al.(5) reported that there was a drop in heart rate and in mean blood pressure when cats inhaled mixed gas of $10 \% \mathrm{CO}_{2}$ and $90 \% \mathrm{O}_{2}$. They suggested that changes in blood pressure might result from sensitivity in the spinal cord to $\mathrm{CO}_{2}$ and/or its sympathetic nerve system connections. Although the present report agrees with Johnson's (5) concerning heart rate and blood pressure, neverthe- 


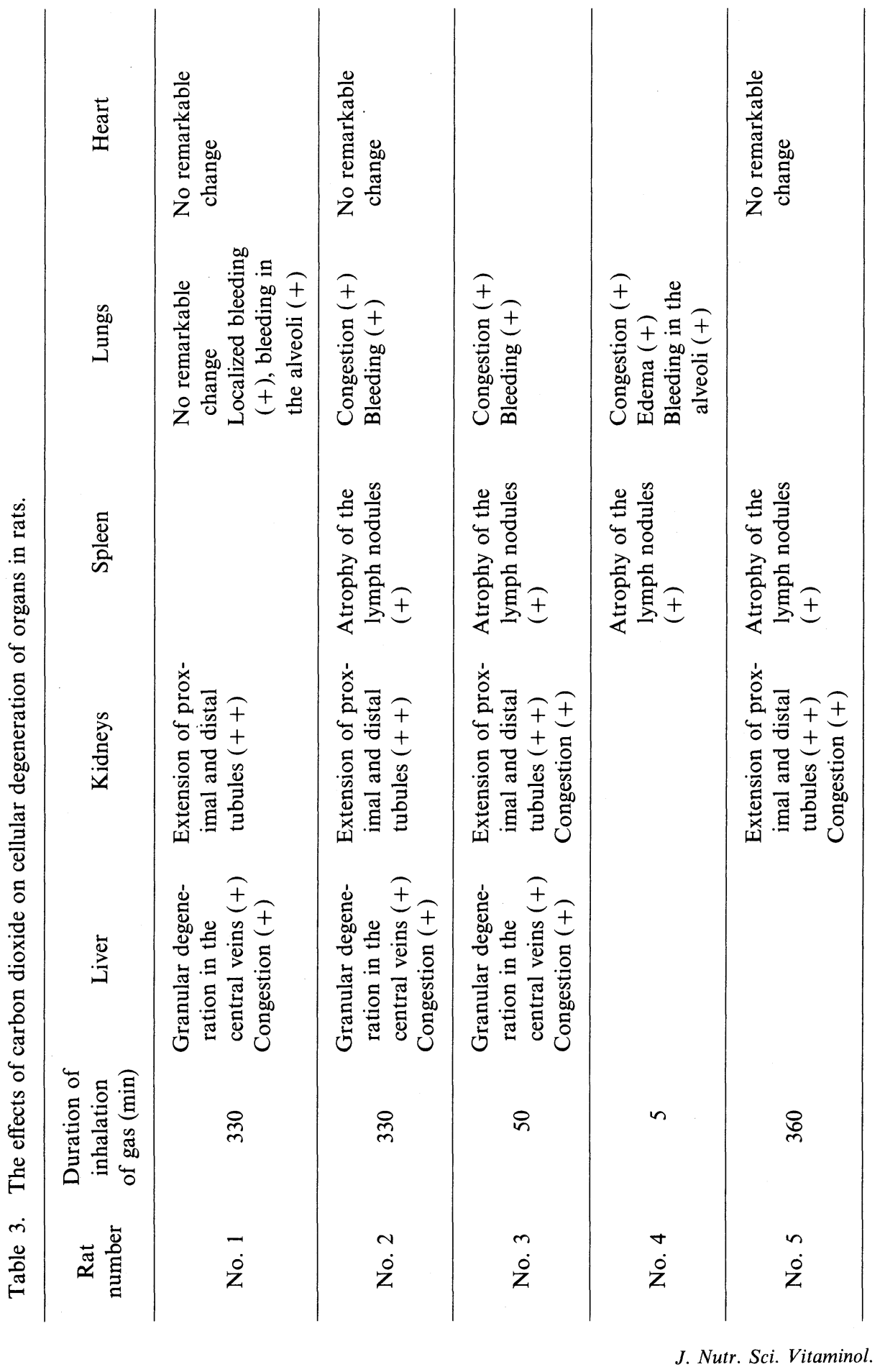




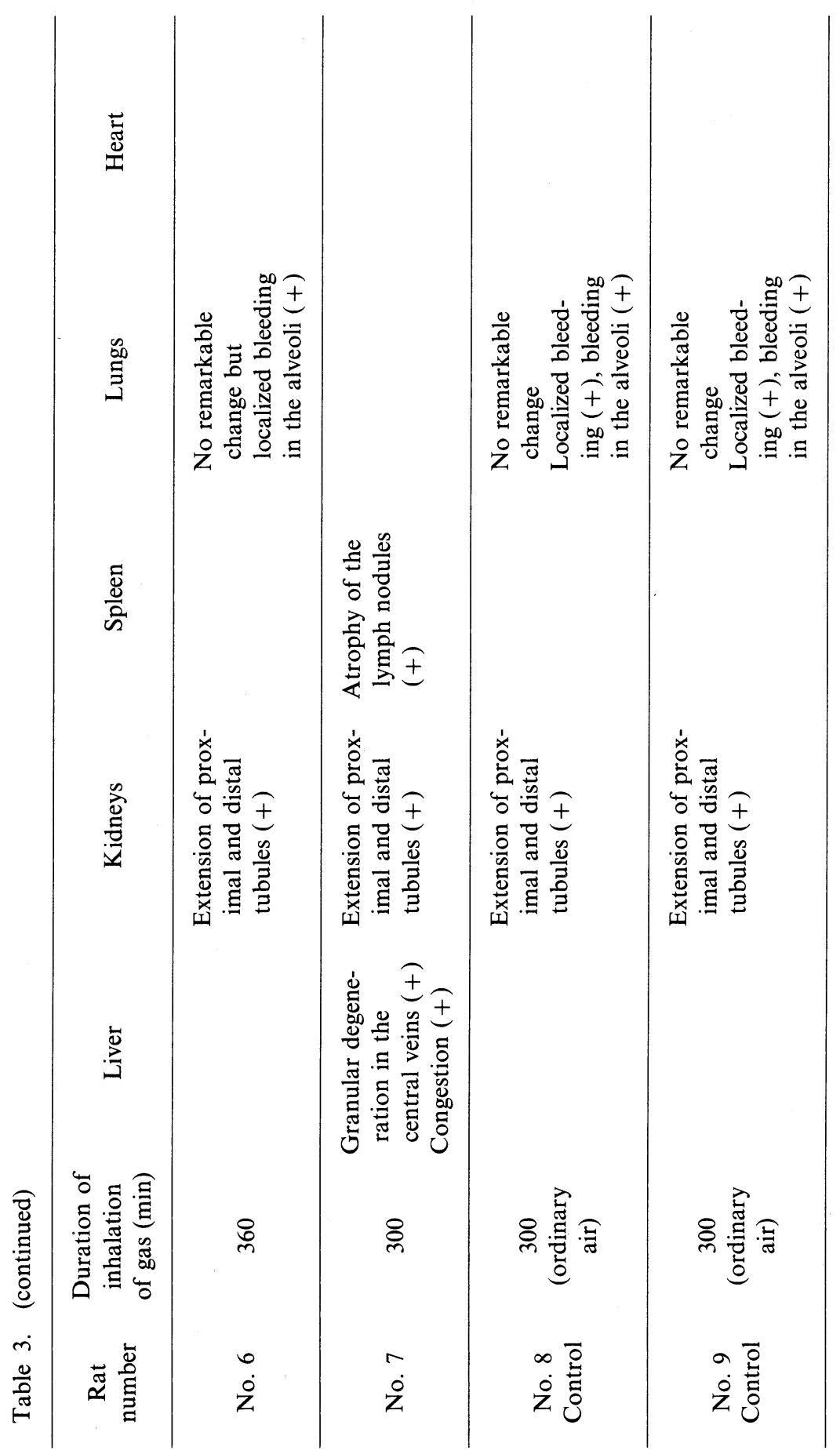

Vol. 28, No. 2, 1982 
less the systems of feedback of $\mathrm{CO}_{2}$ to the heart rate and blood pressure are not clear.

There have been several reports made on rats being exposed to $100 \% \mathrm{CO}_{2}$ for 10 to $25 \mathrm{sec}$. They suffered from severe retrograde amnesia for a task learned during the time immediately prior to the experiment $(6-8)$. Wasterlain $(9)$ found that rats repeatedly exposed to an atmosphere of $\mathrm{CO}_{2}$ for $25 \mathrm{sec}$ had a lower rate of RNA synthesis than the control group. There was a significant difference between the composition of the gas in the case of Wasterlain's experiment and the present one, so it is still unclear whether RNA synthesis was depressed or whether the result was related to variations in serum biological and biochemical patterns. Further studies are necessary to clarify this point.

Though Graham et al. $(2,3)$ found that respiratory arrest occurred when the inhaled carbon dioxide content varied between 23 and $55 \%$ depending upon the preanesthetic used and its concentration, in this study rats were sufficiently anesthetized with up to $40 \% \mathrm{CO}_{2}$ (the remainder being oxygen) for as long as $3 \mathrm{hr}$, probably due in part to lingering effects of the pre-anesthetic pentobarbital. The patterns of $\mathrm{pHa}, \mathrm{PaO}_{2}$ and $\mathrm{PaCO}_{2}$ are interesting when connections are hypothesized between physiological function, level of anesthetic effect, biochemical disorders in organs and cellular degeneration in organs, but the relations between them and their feedback systems are not analyzed here.

One of the most interesting results was that significantly raised levels of several serum biochemical functions returned to normal within only $24 \mathrm{hr}$, so the effects of $\mathrm{CO}_{2}$ can be considered temporary and mild. In addition, the side-effects of $\mathrm{CO}_{2}$ on histopathological forms in several organs were generally mild and presumed to be recoverable when the rats inhaled ordinary air. Further studies are required in order to clarify the nature of these recovery systems.

The authors wish to thank Dr. Kunio Ota, Dr. Goroku Ohta, Dr. Hiroshi Sawazaki and Dr. Mikihiko Tokuriki for their advice and encouragement concerning the overall plan and day-to-day problems which arose during the experiment, and also Dr. J. F. Nunn, Dr. M. K. Sykes, Dr. W. D. A. Smith, Dr. P. Foëx and Dr. C. E. W. Hahn for their valuable suggestions on the anesthesia rendered during the course of the work.

\section{REFERENCES}

1) Hickman, H. H. (1824): Letter on suspended animation, "Experiments, showing that it may be safely employed during operations on animals," to T. A. Knight, printed by Smith, W. D. A. (1981): "Henry Hill Hickman, MRCS (1800-1830) and Anaesthesia," Short essay, pp. 1-11.

2) Graham, G. R., Hill, D. W., and Nunn, J. F. (1959): Circulatory and respiratory responses of dog to progressively increasing concentrations of inhaled carbon dioxide. J. Physiol., 149, 75-76.

3) Graham, G. R., Hill, D. W., and Nunn, J. F. (1959): "Supercarbia" in the anaesthetized dog. Nature, 184, 1071-1072.

4) Mitsuda, H., Kawai, F., and Yamamoto, A. (1971): Hermetic storage of cereals and 
legumes under the water and ground. Mem. Coll. Agric. Kyoto Univ., 100, 49-69.

5) Johnson, R. H., Smith, A. C., and Walter, J. M. (1969): Heart rate and blood pressure of spinal cats inspiring $\mathrm{CO}_{2}$ before and after injection of hexamethonium. Clin. Sci., 36, 257-265.

6) Leukel, F. A., and Quinton, E. E. (1964): Carbon dioxide effects on aquisition and extinction of avoidance behavior. J. Comp. Physiol. Psychol., 57, 267-270.

7) Paolino, R. M., Quartermain, D., and Miller, N. E. (1966): Different temporal gradients of retrograde amnesia produced by carbon dioxide anesthesia and electroconvulsive shock. J. Comp. Physiol. Psychol., 62, 270-274.

8) Taber, R. I., and Banuazizi, A. (1966): $\mathrm{CO}_{2}$-induced retrograde amnesia in a one-trial learning situation. Psychopharmacologia (Berl), 9, 382-391.

9) Wasterlain, C. G. (1970): $\mathrm{CO}_{2}$ anesthesia inhibits RNA synthesis. Brain Res., 21, 452 454. 